\title{
Aviation Safety Concerns for the Future
}

\author{
Brian E. Smith \\ NASA Ames Research Center, Mail Stop 262-11, Moffett Field, CA, 94035, USA \\ Tel: (650.604.6669). Email: Brian.E.Smith@nasa.gov
}

Alfred L.C. Roelen

Netherlands Aerospace Centre, Anthony Fokkerweg 2, 1059 CM, Amsterdam, The Netherlands

Amsterdam University of Applied Sciences, Weesperzijde 190, 1097 DZ, Amsterdam, The Netherlands

Rudi den Hertog

Netherlands Aircraft Company, Hendrik Walaardt Sacréstraat 433, 1117 BM, Schiphol Oost, The Netherlands

doi:10.5296/jss.v2i2.10444

URL: http://dx.doi.org/10.5296/jss.v2i2.10444

\begin{abstract}
The Future Aviation Safety Team (FAST) is a multidisciplinary international group of aviation professionals that was established to identify possible future aviation safety hazards as undesirable consequences of changes. Since 2004, the FAST and its former members have been maintaining a catalogue of 'Areas of Change' (AoC) that could potentially influence aviation safety. The horizon for such changes is between 5 to 20 years. In this context, changes must be understood as broadly as possible. An AoC is a description of the change, not an identification of the hazards that result from the change. An analysis of the AoCs identified in 2004 demonstrates that changes catalogued many years ago, were directly evident in the majority of fatal aviation accidents over the past ten years. This ex-post-facto analysis of the AoCs identified in 2004 demonstrates that changes catalogued previously can provide an opportunity for predicting casual factors of future safety incidents. This paper presents an overview of the current AoC catalogue and a subsequent discussion of related aviation safety concerns. Interactions among these future changes may weaken critical functions that must be maintained to ensure safe operations. Safety assessments that do not appreciate or reflect the consequences of complexity due to such interactions will not be fully informative and can lead to inappropriate trade-offs and increases of other risks. The use of an "Areas of Change" concept permits a systematic analysis of ongoing and future phenomena that may interact with a technology or operational concept under study and generate unanticipated hazards.
\end{abstract}

Keywords: Aviation Safety, Emerging Risks, Change Management 


\section{Background}

In the 1990s, the Joint Aviation Authorities (JAA) in Europe and the Federal Aviation Administration (FAA) of United States sponsored a number of groups to develop interventions aimed at improving safety of the global aviation system. To further this effort, in early 1998 the JAA launched the JAA Safety Strategy Initiative JSSI (JSSI, 2000). The JSSI mission was the continuous improvement of aviation safety in Europe in particular and worldwide in general, leading to further reductions in the annual number of aviation accidents and thus fatalities, irrespective of the fact that air traffic will continue to grow. Safety improvements are first achieved through identification of causal factors, or hazards, and then by taking the necessary steps to eliminate, avoid, or mitigate these hazards. Hazards are defined as events and/or conditions that may lead to a dangerous situation or events and/or conditions that may delay or impede the resolution of such situations. Three complementary approaches are currently used to identify hazards that affect safety of the global aviation system:

- The "Forensic" or "Historic" approach is based on accident and incident investigation and analysis. It uses proven investigative techniques to discover all facts pertinent to an aviation incident or accident, thus identify opportunities for improvements meant to avoid similar events in the future. This is like an aviation autopsy.

- The "Diagnostic" approach is targeted at identifying accident precursors within the larger collections of information from various aviation safety reporting systems. These detection systems are like stethoscopes on the chest of the live aviation "patient."

- A "Prognostic" or "Predictive" approach is aimed at discovering future hazards that could result as a consequence of future changes inside or outside the global aviation system and then initiating mitigating actions before the respective hazards are introduced. The process is like examining the internal biological processes and environmental factors of a patient and then suggesting lifestyle changes to help someone live longer and more productively.

In 1999, the JSSI Steering Group established a dedicated working group to develop and implement methods and processes to support the systematic identification of future hazards. That group was called the Future Aviation Safety Team (FAST). While the FAST is no longer operating under formal remit, NASA and the NLR support continued prognostic safety analysis work by its former members. The current "ex officio" FAST core team includes ten aviation professionals with various backgrounds and expertise from Europe, the U.S. and Canada. In 2004, Bob Kelley-Wickemeyer, Chief Engineer, Safety \& Certification, Performance \& Propulsion (Boeing retired) credited the FAST with originating the forensic-diagnostic-prognostic safety triad described above (Kelley-Wickemeyer, 2004). This paradigm has since been embraced by the International Civil Aviation Organization (ICAO, 2013).

\section{Areas of Change}

In the earliest days of the FAST, one of the principles adopted was that future hazards are undesirable consequences of future changes, and the primary objective of FAST became the 
identification and prioritization of possible future changes that could impact operational safety in the long term. The team finalized a list of 'Areas of Change' (AoC), presenting nearly 150 specific changes that could potentially influence aviation safety (JSSI, 2000). In this context, changes must be understood as broadly as possible. An AoC is a description of the change, not an identification of the hazards that result from the change. AoCs were subsequently prioritized on numerous criteria, i.e., nature and scope of the change, any trends or profiles present or anticipated timing of the considered change and interactions with other areas. A prioritization of the changes was done using the AHP process (Saaty, 2006) in a series of workshops with approximately 90 aviation professionals. The future change with the highest priority was 'Reliance on automation supporting a complex air transportation system' (FAST, 2001).

The FAST AoC list is re-examined on a regular basis by the FAST core team. In addition, the core FAST team continuously monitors the aviation system and the external environment for new AoCs that may arise - a process so-called "horizon scanning." The FAST AoC list is publicly available on a website hosted by the Netherlands Aerospace Centre NLR (http://www.nlr-atsi.nl/fast/aoc/) and currently includes 120 AoCs.

Transformations affecting the future aviation system come in two distinct categories:

- Progressive or rapid-onset physical, functional, and procedural changes that stakeholders plan for the aviation system with the deliberate intention of improving throughput, safety and/or efficiency/economics.

- Unintentional technological innovation, shifting operational tasks, subtle changes in organizations or actors in the system, and contextual factors external to aviation itself that can nonetheless influence the robustness of the support systems upon which operational safety depends.

AoCs are not strictly limited to the future. They may have begun in the past and actually cease at some point in the future. They also may have begun now and continue into the future, or be not yet in place but begin at some near, mid- or far-term timeframe. Here are some examples of Areas of Change to illustrate the concept:

- Accelerating scientific advances enabling improved performance, decreased fuel burn and reduced noise.

- Wake turbulence separation re-categorization.

- Increasing use of Controller Pilot Data Link Communication (CPDLC) for weather information and advisories / clearances.

- Increasing operations of military and civilian unmanned aerial systems in shared airspace.

Changes affecting future aviation safety can come from within the system or from events and circumstances outside aviation - the contextual environment in which aviation operates. Therefore, aviation stakeholders know some transformations, but not others. Those not recognized within the aviation community may nevertheless be known to organizations outside aviation.

AoCs are not hazards per se, but, when combined with other technologies, operational 


\section{Mll Macrothink}

concepts or related AoCs, may become the catalysts for new hazards or modify the probability or severity associated with existing hazards.

\section{Verification of Areas of Change relevance.}

To verify if the AoCs identified in 2004 have indeed become relevant for aviation safety, the FAST analysed worldwide fatal accidents that occurred between 2004 and 2014. The Aviation Safety Network database (https://aviation-safety.net/database/) was used as the initial source of accident information. All fatal accidents involving commercial operations with fixed wing aircraft with a maximum take-off weight heavier than 5,700 kg were included in the analysis. Because the focus of this analysis was on commercial, Part 121 operations, military, ferry/positioning, air ambulance and agricultural operations were excluded. For each accident, the team determined whether AoCs could be associated with the occurrence. To make the analysis tractable and to identify the most significant change effects, a maximum of three AoCs were permitted to be associated with each accident. An association does not necessarily mean that the change caused or contributed to the accident. It merely indicates that the AoC was relevant in the sequence of events that ended-up as an aircraft accident. In addition to the Aviation Safety Network, the team consulted public and non-public sources such as aircraft accident investigation reports, articles in professional magazines (Flight, Aviation Week \& Space Technology, etc.) to obtain information relevant for each accident.

The total set included 247 fatal accidents in 178 (72\%) of which AoCs were assigned. In 69 accidents, none of the AoCs was considered relevant, or a link could not be made, probably because of lack of detailed information about the accident. Out of the 120 AoCs that are currently on the list, 43 (36\%) could be associated with one or more accidents.

The nine most frequently assigned AoCs are listed in Table along with the relative percentage of the AoCs analysed in 2004 (FAST, 2004a) across the full set of 247 accidents.

Table 1. Frequency of AoC in the Total Accident Set $(\mathrm{N}=247)$.

\begin{tabular}{|l|l|l|}
\hline Description of Area of Change (2004) & $\begin{array}{l}\text { Accident } \\
\text { Count }\end{array}$ & $\begin{array}{l}\text { Percentage } \\
\text { of Total Set }\end{array}$ \\
\hline Socio-economic and political crises affecting aviation & 48 & 19.4 \\
\hline Operation of low-cost airlines & 44 & 17.8 \\
\hline Smaller organisations and owners operating aging aircraft & 42 & 17.0 \\
\hline $\begin{array}{l}\text { Reliance on automation supporting a complex air transportation } \\
\text { system }\end{array}$ & 40 & 16.2 \\
\hline Increasing operations of cargo aircraft & 39 & 15.8 \\
\hline Increasing reliance on procedural solutions for operational safety & 19 & 7.7 \\
\hline $\begin{array}{l}\text { Operational tempo and economic considerations affecting flight } \\
\text { crew alertness }\end{array}$ & 16 & 6.5 \\
\hline Accelerated transition of pilots from simple to complex aircraft & 10 & 4.0 \\
\hline $\begin{array}{l}\text { Decreasing availability of qualified maintenance staff at stations } \\
\text { other than home base of operations }\end{array}$ & 8 & 3.2 \\
\hline
\end{tabular}




\section{Aviation Safety Concerns for the Future}

The analysis described in the previous section demonstrates that changes catalogued many years previously were directly relevant to the majority of fatal aviation accidents over the past ten years. It is therefore important to consider the current AoC list for identifying possible aviation safety concerns for the future. The safety concerns that have been identified by the FAST as most pertinent are described in the following sections. These fit into the following broad thematic areas:

- Global Air-Ground-Space System

- Flight-crew/Automation Interaction Issues

- General Threats

- Fully Automatic Flight ${ }^{1}$

\subsection{In-Service Inertia}

For many aircraft and ground ATC and space systems now in use, there is a growing understanding that these technological systems will be in production and operation far longer than ever conceived by their designers. This in-service 'inertia' acts as a moderator/constraint to automation evolution. Largely due to airline economic factors, the life span of commercial aircraft and their flight decks is known to be much longer than commonly imagined. The projected future fleet of more than 22,000 Boeing 737 and Airbus 320 single-aisle aircraft by 2025 is an example (Airbus, 2015; Boeing, 2015). Thus, manufacturers may lack the business case to produce aircraft that push technology/automation envelopes. The same constraints of infrastructure inertia will be true for the many existing ground and space automation systems upon which many of the future Air Ground Space (AGS) elements under development within the Single European Sky Air traffic management Research (SESAR) and U.S. NextGen air traffic control modernization programs will depend. Increasing heterogeneity will require preventive actions. Designers, researchers, regulators, and operators may have left the aviation industry long before the last derivative enters service and hence essential information on the subtleties of the design of highly-automated software and electromechanical systems, related training, and operational lessons learned may be lost.

\subsection{The Prosperity Factor}

The strength of the economy of the country of the operator is a dominant influence factor, explaining for most of the differences in accident rates across geographical region (Visser, 1997). This finding indicates that addressing the traditional 'human factors' will not succeed in bringing down accident rates worldwide if the economic environment in which individual airlines operate (the 'prosperity factor') is left untouched. This may require a dedicated task force (e.g. a Joint Safety Implementation Team) to develop and recommend an AoC-based action plan for industry and governments to support poorer countries in implementing recommended safety enhancements, such as improved weather forecasts, new runway safety

\footnotetext{
${ }^{1}$ Fast analyzed the concept of Fully Automatic Flight (FAF) which was only allowed by the JSSI steering group as the "ultimate form of automation" even though most, if not all of them - except the FAST team - felt that commercial flight completely without pilots would ever be allowed. This was also driven by unmanned Aerial Vehicles (UAV) and drones that were shown as early as 2002 .
} 
features for critical runways, fewer Non-Directional Beacon (NDB) approaches, replacement of the old fashioned Instrument Landing System (ILS) by the much cheaper and more advanced Microwave Landing System (MLS).

\subsection{Cosmic Cycles of Accidents}

Organisations occasionally have memory lapses. They forget how early program phases were driven, what the difficulties were, and quasi-systematically, they fall prey to the same errors. (Ballesteros, 2007) Critical knowledge to carry out operations, maintenance and inspection, in terms of know-how and know-why, appears to fade over time. Between two programs involving new systems and new management, there may be several decades. Lost competencies and the complexity of industrial structures affect primarily early phases of a program, leading to insufficient or wrong assumptions affecting the entire life cycle. Because lessons learned tend to be isolated in lower levels of an organization and perishable, rather than generalized and institutionalized, programs may repeatedly suffer from the same disease. This is especially true in situations in which operational safety relies on procedural solutions, such as when to perform ground de-icing and identifying standard operating procedures and training for stall recognition and upset recovery. Drift into failure of an organisation due to lost competencies and increasing complexity is hard to recognise because it is about normal people doing normal work in (seemingly) normal organizations (Dekker, 2005).

\subsection{Next Generation of Pilots}

There will be problems with maintaining "hands-on" currency due to future advances in flight deck automation. Worldwide economic pressures to recruit pilots for Part 121 operations will likely result in more rapid transition of trainees from simple to complex aircraft (McGee, 2015). Current certification standards may need to be revisited in light of this phenomenon. Training curricula must provide the skills needed for command of complex, advanced aircraft. This phenomenon is evident in proposals for Multi-Crew Pilot License (MCPL) (Schroeder \& Harms, 2007). Fewer commercial pilots will be available who have benefitted from a military background. It will be critical to develop training approaches to make up for the lack of experience of pilot candidates in recovery from unusual attitudes or unexpected situations. These training approaches should address the important issue of candidates' transition, or even initial introduction, to ever more complex aircraft.

\subsection{Safety Oversight}

Analysis of 42 accidents involving small low cost airlines showed that at least half of the airlines had one or more accidents before (Smith et al, 2016). This suggests that continuous airline oversight of low-cost airlines by the authorities remains challenging. Both ICAO and EASA intend to implement Performance Based Regulation (PBR) and Performance Based Oversight (Sayce, 2014). PBR revolves, amongst other things, around the definition of so-called Key [safety] Performance Indicators (KPI). However, definition of KPI's does require knowledge of the past, i.e. know-why of the requirements. As mentioned previously, there is no known repository of why the rules have been designed as such, including later modifications. 
4.6 Reliance on Automation Supporting a Complex Air Transportation System

In 2004, the FAST conducted a study of the topic, "Increasing reliance on flight deck automation" at the behest of the JSSI (FAST, 2004a), which resulted in 21 prioritized (out of 286) hazards ${ }^{2}$. In addition, the FAST conducted a survey among more than 190 commercial pilots, with a mean of 10,000 flying hours and 20 years' business experience (FAST, 2004b). The survey examined hazards associated with:

1. Relevance and establishment of level of manual flying skills associated with current levels of flight deck automation.

2. Training requirements as a result of advances in flight deck automation.

3. Safety, human factors \& operational procedures.

Although the change towards an increasing reliance on flight deck automation has been a major factor in the current favorable safety record of western commercial aviation (CAST, 2013) the misuse/misunderstanding of automated systems and their flight-deck interfaces has been evident in certain high-profile accidents (Table 2).

Table 2. Automation Surprise in Fatal Accidents

\begin{tabular}{|c|l|l|l|l|l|}
\hline & $\begin{array}{c}\text { Colgan Air } \\
\text { Q400 } \\
\text { Feb 12, 2009 } \\
\text { (NTSB, 2010) }\end{array}$ & $\begin{array}{l}\text { Turkish Airlines } \\
\text { B737-800 } \\
\text { Feb 25, 2009 } \\
\text { (DSB, 2010) }\end{array}$ & $\begin{array}{c}\text { Air France } \\
\text { A330 } \\
\text { June 1, 2009 } \\
\text { (BEA, 2012) }\end{array}$ & $\begin{array}{c}\text { Asiana } \\
\text { B7777 } \\
\text { July 6, 2013 } \\
\text { (NTSB, 2014) }\end{array}$ & $\begin{array}{c}\text { Air Asia } \\
\text { A320 } \\
\text { Dec 28, 2014 } \\
\text { (KNKT, 2015) }\end{array}$ \\
\hline $\begin{array}{c}\text { Manner by } \\
\text { which } \\
\text { automation } \\
\text { surprise } \\
\text { was } \\
\text { evident }\end{array}$ & $\begin{array}{l}\text { Crew was } \\
\text { surprised by } \\
\text { stick-pusher } \\
\text { operation and } \\
\text { responded } \\
\text { inappropriate } \\
\text { ly. }\end{array}$ & $\begin{array}{l}\text { Crew was } \\
\text { unaware that } \\
\text { auto-thrust } \\
\text { reduction } \\
\text { was } \\
\text { triggered by } \\
\text { faulty radio } \\
\text { altimeter. }\end{array}$ & $\begin{array}{l}\text { Aircraft } \\
\text { response to } \\
\text { control input } \\
\text { when in } \\
\text { alternate law } \\
\text { at high } \\
\text { altitude was } \\
\text { not } \\
\text { understood } \\
\text { by crew. }\end{array}$ & $\begin{array}{l}\text { Crew failed } \\
\text { to recognize } \\
\text { that } \\
\text { selection of } \\
\text { the autopilot } \\
\text { mode } \\
\text { cancelled } \\
\text { the } \\
\text { auto-thrust } \\
\text { speed } \\
\text { protection. }\end{array}$ & $\begin{array}{l}\text { Crew failed } \\
\text { to recognize } \\
\text { that pulling } \\
\text { the circuit } \\
\text { breakers } \\
\text { in-flight } \\
\text { keeps the } \\
\text { aircraft in } \\
\text { alternate } \\
\text { law. }\end{array}$ \\
\end{tabular}

In each of the accidents listed in Table 2, automation surprises led the crews away from appropriate actions. It is yet unclear whether revised training - e.g., upset recovery training-, new procedures or design changes can prevent the occurrence of such cases in the future, because we do not fully understand human decision making in unusual situations (Lamme, 2010).

Although the study was conducted in 2004, its findings and recommendations are as relevant now as then, as evidenced by the recent automation surprise accidents shown in Table 2. The hazard assessment methodology examined both principal hazards inherent within the flight deck automation topic as well as hazards arising from interactions with related AoCs. Two

\footnotetext{
2 See top of page 3 of http://nlr-atsi.nl/fast/downloads/Fast\%20phase\%203\%20issue\%2010\%20Exec\%20Sum24-01-04.pdf
} 
systematic processes were used to facilitate this hazard identification exercise: (1) Domain experts and generalists suggested possible hazards to crew, passengers, third parties, etc., and (2) Structured brainstorming. Dependencies among AoCs that could create hazards via the so-called cascade effect were also identified.

\section{Technology Watch Items}

An integral part of the FAST methodology is the definition of Technology Watch Items (TWI). TWIs can provide tell-tale signals if a postulated future is coming about. They include not just technical items, but "social science" items and business/affordability perspectives. For example, the 2009 FAST Handbook described a potential Technology Watch Item in these terms: “...the Military will be fielding new navigation technology, GPS, which if applied to civilian airplanes, will significantly increase the lateral precision with which airplanes will fly intended airways. Airplanes will then be closer to each other vertically and laterally. In this case, collision and/or wake vortex upset risk may significantly increase. If you see intentions to adopt GPS technology for civil transport navigation (watch item), then we recommend that studies are conducted and the industry agrees to mitigating practices such as intentional cross-track stagger. Care should be taken when doing so to ensure that wind direction is considered in the study."

Back in 2004, the FAST report also suggested examining other fields of technologies such as "eSafety of road and air transport" for signs that emerging technologies may generate novel hazards. Today, self-driving cars are being tested by Google and are already in service from Tesla. As could be expected, "eSafety” is already an issue for a recent set of accidents (Silk, 2016). While a potential list of issues that spring to mind would be rather long, there are two that could have an immediate spin-off to the aerospace industry, notably:

a) Emergence of novel business models and markets, for instance for car insurance and product liability. The automotive industry could move to e.g. all risk insurance for all vehicles thus creating time to solve the issue whether this would be a driver- or manufacturer mistake. Likewise, carmakers must find ways to obtain acceptable product liability insurance. Before $1994^{3}$, single piston engine aircraft makers reverted to producing aircraft kits that were only $49 \%$ complete. This put the assembler of the $51 \%$ remaining aircraft "in charge" of ultimate product liability, otherwise costs of litigation were unsurmountable.

b) Rapid advances in artificial intelligence including self-learning systems that enable detection and avoidance of unusual objects on the road. There is a tremendous amount of work ongoing in this area (Matthei et al., 2011) In light of these technology advances, today's verification and validation tools used to certify software systems need radical improvement. Many future systems will feature non-deterministic behaviour that is not amenable to analysis by conventional methods. This is primarily driven by the vast number of permutations that defy conventional verification and validation techniques.

\footnotetext{
${ }^{3}$ This practice stopped after "The Aviation Revitalization Act” on 1994
} 


\section{Conclusions}

The analysis of key Areas of Change presented in this paper demonstrate that phenomena catalogued many years previously were directly implicated in the majority of fatal aviation accidents over the past ten years. AoCs as utilized in this paper form a predictive approach that combines the following dimensions (op cit., 2007):

- Looking forward, e.g. through forecasting, trend analysis, gaming and scenarios, and futurist writing.

- Looking across, e.g. through systemic thinking across multiple domains that reflect technology convergence.

- Looking backwards, through historical analogy, previous future-oriented studies, trend, and analysis. History is important, although it shouldn't be the sole basis for the identification and analysis of future risks.

- Finally, there also needs to be a) a concerted effort "to prepare" the recipient of the prognostic message(s), and b) continuous processing of signalled problems in a follow-on team. This is an essential strategy for success.

One major difficulty with the assessment of future risks is to predict the future system with enough certainty and provide a good, complete and trustable description of the future. Although the future can never be entirely predicted, certain changes are likely to happen, such as the introduction of 4D trajectory management and System Wide Information Management (SWIM) into Air Traffic Management. These 'solid' elements can then be combined with less certain elements (e.g. demographics, fuel price changes, socio-technical-cultural factors) to form various scenarios from collections of future changes.

Collections of changes affecting aviation such as maintained by the FAST can be important catalysts for assessment of the following predictive safety questions described in the FAST Handbook (op cit., 2009):

1. How do the Areas of Change, in isolation or in combination, introduce or affect the hazards and risks from traditional system safety assessments?

2. Are there novel emergent hazards generated by interactions between and among AoCs that could adversely impact the safety characteristics of the future system being assessed? Interactions among these future changes may weaken critical functions that must be maintained to ensure safe operations. Critical functions are defined as potential pathways leading to successful management of emerging risk rather than simply preventing failure. Assessments that do not appreciate or reflect the consequences of interaction complexity will not be fully informative and can lead to inappropriate trade-offs and increases in other risks (IRGC, 2010).

3. How does one contrast the potential benefits of intentional changes being adopted by stakeholders for safety and efficiency objectives against the potential unintended, adverse consequences of those changes that arise from unforeseen interactions with other elements of the aviation system?

4. How do the Areas of Change, in isolation or in combination, affect the robustness or resilience of the risk controls (barriers) being considered?

5. The use of AoCs provides a different view on accidents as they happen worldwide since it 
triggers questions like a) how does the industry ensure information availability for operations, maintenance \& overhaul, b) if human factors work will not bring down world-wide accident rates in view of the economic environment, we should review and consider changes to the current safety efforts addressing e.g. 'loss of control' accidents.

6. Technology Watch Items may become tell-tale indicators that certain futures are coming about and it may help to look into other technologies as well.

7. Are there weak signals that should be acted upon? A great deal of work is currently taking place to improve our ability to sense and recognize signals of change in conditions or processes that are weak or masked but operationally significant.

Areas of Change help an analyst adopt a prospective mind-set: an ability to project oneself into the future; i.e. reflect within a framework that is unknown or uncertain. Many FAST Areas of Change that were identified in 2004 are related to the examined set of fatal accidents over the past ten years. The "Prognostic" or "Predictive" approach aims to uncover such relations, and the present analysis demonstrates the value of such a look-ahead. Examining future changes enables discovery of future hazards by collecting changes inside and/or outside the global aviation system. Once such hazards have been identified, mitigating actions can be initiated before the hazard appears. Prognostic hazard identification informs design processes so that the hazards can be eliminated, avoided or mitigated in the future. The FAST Areas of Change inventory will be a great help in this endeavor.

\section{References}

Airbus. (2015). Flying by numbers 2015 2034, Global Market Forecast, Airbus S.A.S., Blagnac Cedex, France.

Ballesteros, J. S. (2007). Improving air safety through organizational learning. Burlington, VT: Ashgate Publishing, April 2008.

BEA. (2012). Accident of an Airbus A330-203 registered F-GZCP and operated by Air France crashed into the Atlantic Ocean, BEA f-cp090601, Bureau d'Enquêtes et d'Analyses pour la sécurité de l'aviation civile, Paris, France.

Boeing. (2015). Current Market Outlook 2015-2034, Boeing Commercial Airplanes, Seattle, WA, USA.

Cagnin, C., Scapola, F. (2007). Technical Report on a Foresight Training Course, EUR 22737 EN, Institute for Prospective Technological Studies, Joint Research Centre, Seville, Spain.

Commercial Aviation Safety Team (CAST) (2013), Report on the Operational Use of Flight Path Management Systems, report of the Flight Deck Automation Working Group within the Commercial Aviation Safety Team, September 2013.

Dekker, S. (2005). Why we need new accident models, Technical Report 2005-02, Lund University School of Aviation, Sweden.

FAST. (2001). FAST second phase final report. Retrieved on 20 January 2016 from http://www.nlr-atsi.nl/fast/downloads/ 
FAST (2004a). Report on the phase 3 of the work of the Future Aviation Safety Team, Increased reliance on flight deck automation. Retrieved on 20 January 2016 from http://www.nlr-atsi.nl/fast/downloads/

FAST (2004b). Airline Industry Survey of Hazards Associated with Reliance on Flight Deck Automation, Retrieved on 20 January 2016 from http://www.nlr-atsi.nl/fast/downloads/

FAST (2009). The FAST Approach to Discovering Aviation Futures and Associated Hazards: Methodology Handbook, Retrieved on 31 October 2016 from http://www.nlr-atsi.nl/fast/downloads/FAST_Handbook_073009\%20_2.pdf

Hakkeling-Mesland, M.Y., Bos, T.J.J., Roelen, A.L.C. (2005). Onderzoek inzake niet-vastleggen technische klachten door vliegers, NLR-CR-2005-164, NLR Amsterdam. (in Dutch)

IRGC. (2010). Risk governance deficits: analysis, illustration and recommendations: policy brief. International Risk Governance Council, Geneva, Switzerland.

JSSI (2000). Future hazards working group report, retrieved on 20 January 2016 from http://www.nlr-atsi.nl/fast/downloads/

ICAO. (2013). Safety Management Manual, Doc 9859, third edition. International Civil Aviation Organization, Montreal, Canada.

Kelley-Wickemeyer, Bob. (2004). A Large Commercial Jet Transportation Perspective, presentation to the FAST, 2 March 2004.

KNKT (2015). Aircraft Accident Investigation Report. Indonesia Air Asia, Airbus A320-216; PK-AXC, Karimata Strait, Coordinate 3³7’19”S - 10942’41’E, Republic of Indonesia, 28 December 2014. Komite Nasional Keselamatan Transportasi, Jakarta, Republic of Indonesia.

Lamme, V. (2010). De vrije wil bestaat niet. Bert Bakker. (in Dutch)

Levinson, Jesse, et al. (2011), Towards Fully Autonomous Driving: Systems and Algorithms Carnegie Mellow University,

Matthai, Richard, Lichte, Bernd \& Maurer, Markus (2013), Robust Grid-Based Road Detection for ADAS and Autonomous Vehicles in Urban Environments, Institute for Control Engineering Technische Universität Braunschweig Braunschweig, Germany, July 20, 2013

McGee, Michael (2015), Air Transport Pilot Supply and Demand Current State and Effects of Recent Legislation, Pardee RAND Graduate School (PRGS) dissertation, 2015, RAND Corporation, Arlington VA, USA.

NTSB. (2010). Loss of Control on Approach, Colgan Air, Inc., Operating as Continental Connection Flight 3407, Bombardier DHC-8-400, N200WQ, Clarence Center, New York, February 12, 2009. AAR-10/01. National Transportation Safety Board, Washington, D,C., USA.

NTSB. (2014). Descent Below Visual Glidepath and Impact With Seawall, Asiana Airlines 


\section{Macrothink}

Journal of Safety Studies

ISSN 2377-3219

2016, Vol. 2, No. 2

Flight 214, Boeing 777-200ER, HL7742, San Francisco, California, July 6, 2013. AAR-14/01 National Transportation Safety Board, Washington, D,C., USA.

Roelen, A.L.C., Pikaar, A.J., Ovaa, W. (2001). An analysis of the safety performance of air cargo operators, Flight Safety Digest, Vol. 20, pp. 1-16.

Saaty, T.L. (2006). Fundamentals of Decision Making; the Analytic Hierarchy Process. RWS 3 Publications, Pittsburgh, PA, USA.

Sayce, Adrian (2014) Raising Safety Standards \& Transforming to Performance Based Regulation, Civil Aviation Authority international (CAAi), UK CAA, September 30, 2014.

Schroeder, Capt. Chris \& Harms, Capt. Dieter (2007), MPL represents a state-of-the-art ab initio airline pilot training programme, ICAO Journal, Vol. 62, No. 3, May/June 2007

Silk (2016), Monthly Updated Data on Google Car Crash Reports, https://google-self-driving-car-incidents.silk.co, retrieved on November 29, 2016

Smith, B.E., den Hertog, R., Roelen, A.L.C. (2016). Transformational Phenomena as Predictors of Aircraft Accidents: What Goes Around Comes Around. In Proceedings of the 50th ESReDA Seminar, Seville, Spain.

Visser, H.C. (2013). If I were a rich man...my accident record wouldn't be so bad! In Soekkha, H.M. (ed.), Aviation Safety, VPS, pp. 365-389.

\section{Copyright Disclaimer}

Copyright for this article is retained by the author(s), with first publication rights granted to the journal.

This is an open-access article distributed under the terms and conditions of the Creative Commons Attribution license (http://creativecommons.org/licenses/by/3.0/). 